\title{
Correction to: Kinematics and kinetics of handcycling propulsion at increasing workloads in able-bodied subjects
}

\author{
Oliver J. Quittmann ${ }^{1} \cdot$ Joshua Meskemper ${ }^{2}$. Thomas Abel ${ }^{1,3} \cdot$ Kirsten Albracht $^{2,4} \cdot$ Tina Foitschik $^{1}$. \\ Sandra Rojas-Vega ${ }^{1} \cdot$ Heiko K. Strüder ${ }^{1}$
}

Published online: 29 May 2018

(c) International Sports Engineering Association 2018

\section{Correction to: Sports Engineering}

$$
\text { https://doi.org/10.1007/s12283-018-0269-y }
$$

In the original article, the surname of the second author is published incorrectly. The correct author name should be "Joshua Meskemper".

The original article is updated with the correct author name.

The original article can be found online at https://doi.org/10.1007/ s12283-018-0269-y.

Oliver J. Quittmann

o.quittmann@dshs-koeln.de

1 Institute of Movement and Neurosciences, German Sport University Cologne, Am Sportpark Müngersdorf 6, 50933 Cologne, Germany

2 Institute of Biomechanics and Orthopaedics, German Sport University Cologne, Cologne, Germany

3 European Research Group in Disability Sport (ERGiDS), Cologne, Germany

4 Faculty of Medical Engineering and Technomathematics, FH Aachen University of Applied Sciences, Aachen, Germany 